\title{
MULTI-SATELLITE OBSERVATION OF MEGH CYCLONE
}

\author{
Jagdish $^{1,2, *}$, Jinya John ${ }^{1}$, Bipasha Paul Shukla ${ }^{1}$ and Raj Kumar ${ }^{1}$ \\ ${ }^{1}$ Earth, Ocean, Atmosphere, Planetary Sciences and Applications Area, Space Applications Centre, Indian Space Research \\ Organisation, Ahmedabad, India - (jagdishisro, jinyajohn14, bipasha, rksharma)@ sac.isro.gov.in
}

${ }^{2}$ Department of Mathematics, University School of Sciences, Gujarat University, Ahmedabad, India - jagdish.aug1991@gmail.com

Commission V, SS: Atmosphere, Ocean, Weather and Climate

KEY WORDS: Cyclone, Megh, RISAT-1, Synthetic aperture radar, cloud microphysics, Wind speed.

\begin{abstract}
:
Cyclone Megh, a category-3 (Saffir-Simpson scale) cyclonic storm is regarded as the worst tropical cyclone to ever strike Yemen's island of Socotra. In this paper, we aim to investigate the wind structure of cyclone Megh using Synthetic Aperture Radar (RISAT-1 SAR) observations. An algorithm for the cyclone wind retrieval has been applied for SAR data of Nov 8, 2015 at 0238:09 UTC in the Arabian Sea. The intensity of cyclone is $30 \mathrm{~m} / \mathrm{s}$ with the $16.65 \mathrm{~km}$ radius of maximum wind speed from the centre of the cyclone. The high resolution SAR data analysis bring to focus the possible presence of eyewall mesovortex in case of Megh. Recent work has shown that vorticity mixing in the tropical cyclone (TC) inner core can promote mesovortex (MV) formation and impact storm intensity. This has further been corroborated using INSAT-3D and MODIS optical band observations of clouds. Analysis of these satellite derived cloud microphysical properties shows the presence of larger hydrometeors surrounding the eye due to possible embedding of stratus and stratocumulus cloud decks. Thus, this kind of study helps in understanding the microphysical processes within a TC as well estimating their impacts on cyclone intensity and lifetime.
\end{abstract}

\section{INTRODUCTION}

Satellite remote sensing of wind speed via multi-sensors, such as scatterometers, radiometers, and synthetic aperture radar (SAR), has contributed accuracy to weather forecasts. The superior high spatial resolution of SAR is unique for mesoscale wind speed monitoring in coastal areas. Recently, C-band cross-polarized ocean backscatter has been documented as being insensitive to the wind direction or the radar incidence angle, and quite linear with respect to the wind speed, and thus can be used to directly retrieve wind speeds (Zhang et. al, 2011). An empirical C-band Cross Polarization (C-2P) backscatter model was developed to retrieve high resolution ocean surface wind speed from RISAT-1 SAR data, which eliminates the need for radar incidence angle inputs and provides a linear response at high wind speeds for tropical cyclones (Jagdish et. al, 2018a).

It is also interesting to examine the cloud microphysical structure within a TC. Different types of cloud systems are present within different regions of a cyclone and consequently different microphysical processes occur spatially throughout the TC extent. The eye is the region of low level clouds whereas eyewall and rainbands consist mostly of deep convective clouds (Houze, 2014). Studies have revealed that slight precipitation is associated with the eye and its diameter is related to the TC intensity (Franklin, 1988 and Lander,1999). In contrast, the eyewall and rainbands are regions of heavier precipitation (Cecil et. al, 2002). Moreover, the phase and spatial distribution of cloud and precipitation particles above the $0^{0} \mathrm{C}$ isotherms in three Atlantic hurricanes has been analysed through aircraft observations and it was found that ice particles were present largely in convective and stratiform areas of the storm (Black et al, 1986). In addition to observational analyses, model simulations have shown differences in size distributions in different regions of TC (Farquhar et. al, 2004). A proper understanding of different microphysical processes during cyclone events is still required. Thus, to a large extent this could be achieved by examining satellite derived cloud microphysical parameters (CMPs). Since satellite observations offer the advantage of global coverage of events, it is possible to analyse and understand the cloud microphysical characteristics of different synoptic scale events. Thus, in this regard, two main CMPs such as cloud optical thickness (COT) and cloud effective radius (CER) of TC Megh using observations from two satellite sensors are examined in this study.

TC Megh was an extremely severe cyclone that formed in the Arabian Sea on 5 November, 2015 and weakened on 10 November, 2015 after making landfall at Somalia and Socotra. It was a category-3 cyclone on Saphir Simpson scale. The 1minute maximum sustained wind speed was $205 \mathrm{~km} / \mathrm{hr}$ and 3 minute wind speed was $175 \mathrm{~km} / \mathrm{hr}$.

\section{DATA AND METHODOLOGY}

RISAT-1 has come up with a potential to monitor vegetation, coastal and Cryosphere. It is designed to image the Earth's surface in different modes i.e., HRS (High Resolution SPOTLIGHT), FRS-1(Fine Resolution STRIPMAP), FRS-2 (Fine Resolution Alternate Polarization STRIPMAP), MRS (Medium Resolution SCANSAR) and CRS (Coarse Resolution SCANSAR) of swath widths ranging from 30 to

\footnotetext{
* Corresponding author
} 
$240 \mathrm{~km}$ (Jagdish et. al, 2018b). The Key datum for this study are RISAT-1SAR data. SAR image used in this study, is processed at Space Applications Centre, ISRO. The image is georeferenced CRS ScanSAR products with a pixel spacing of $36 \mathrm{~m}$ (range) $\times 36 \mathrm{~m}$ (azimuth). RISAT-1 provides verticaltransmit and vertical-receive (VV polarization) data. The

Table 1. Basic Megh cyclone information derived from RISAT-1 SAR.

\begin{tabular}{|c|c|c|c|c|c|c|c|c|c|c|}
\hline Date & $\begin{array}{l}\text { Time } \\
\text { (UTC) }\end{array}$ & $\begin{array}{c}\mathrm{TC} \\
\text { Location }\end{array}$ & $\begin{array}{c}\text { Centre } \\
\text { Lat }\end{array}$ & $\begin{array}{c}\text { Centre } \\
\text { Lon }\end{array}$ & $\begin{array}{c}\text { Categor } \\
y\end{array}$ & $\mathrm{~V}_{\max }$ & Pressure & $\begin{array}{l}\text { Shape } \\
\text { Of eye }\end{array}$ & $\begin{array}{l}\text { Area } \\
\text { Of eye }\end{array}$ & SAR \\
\hline 08-11- 2015 & 0238 & $\begin{array}{c}\text { Arabian } \\
\text { Sea }\end{array}$ & 12.42 & 55.38 & 3 & $\begin{array}{l}30 \\
\mathrm{~m} / \mathrm{s}\end{array}$ & $964 \mathrm{hPa}$ & Elliptic & $\begin{array}{c}871 \\
\text { sq.km }\end{array}$ & $\begin{array}{c}\text { RISAT- } \\
1\end{array}$ \\
\hline
\end{tabular}

spatial resolution and swath of a CRS image are $25 \mathrm{~m}$ and 223 $\mathrm{km}$, respectively. The image is acquired during November 8 , 2015 at 0238:09 UTC in the Arabian Sea near Socotra Island. The detailed methodology of retrieving tropical cyclone wind can be found in (Jagdish et. al, 2018a). The detailed information about cyclone Megh can be review in Table 1 .

INSAT-3D derived CER and COT have been used in the present work. They are estimated from shortwave infrared (SWIR) and visible channels of INSAT-3D imager at $4 \mathrm{~km}$ spatial resolution. The retrieval is based on a look-up-table (LUT) approach (John et. al, 2016). The physical basis of their retrieval is that the reflectance in the visible region is mainly a function of cloud optical thicknesses and the reflectance in the SWIR region is primarily a function of cloud effective radius. Moreover, Moderate Resolution Imaging Spectro-radiometer (MODIS) data has been also used. MODIS is a 36 band spectroradiometer on board Aqua/Terra platforms. It provides data products at $250 \mathrm{~m}, 500 \mathrm{~m}$ and $1000 \mathrm{~m}$ spatial resolutions. For the present work, CER derived at $1 \mathrm{~km}$ spatial resolution has been used. Using both datasets, the spatial distribution of CMPs has been investigated. This has been done by extracting COT and CER acquired during November 8, 2015 at 0600 UTC of INSAT-3D. Further, using MODIS granule acquired at 0735 UTC of November 8, 2015, a transect passing through the centre of TC has been extracted. The variation of CER along this transect has been examined.

\section{RESULTS AND DISCUSSION}

Fig 1a shows the NRCS retrieved from RISAT-1 SAR. Fig. 1b shows the wind speed retrieved from the RISAT-1. NRCS values are converted to wind speed using developed GMF, $\mathrm{C} 2 \mathrm{P}$ at Space Applications Centre (SAC). The intensity and radius of maximum wind speed from centre of the cyclone were found $30 \mathrm{~m} / \mathrm{s}$ and $16.65 \mathrm{~km}$, respectively. Fig. $2 \mathrm{a}$ and $2 \mathrm{~b}$ show the transect plot of wind speed passing through the centre of cyclone along longitude and latitude. It can be clearly seen in Fig 2, there are two minima followed by a maxima in the eyewall. The observed maxima in eyewall is designated as the mesovortex.

Interestingly, however, the dynamics behind mesovortex generation remains an open research problem. Note that the relationship between mesovortices, damaging winds, and tornadoes has been reviewed. With one exception [Wakimoto et. al, 2006], studies of mesovortex-genesis have been based upon numerically simulated convective systems. Several distinct conceptual models have emerged for mesovortex formation [Schenkman and Xue, 2016].
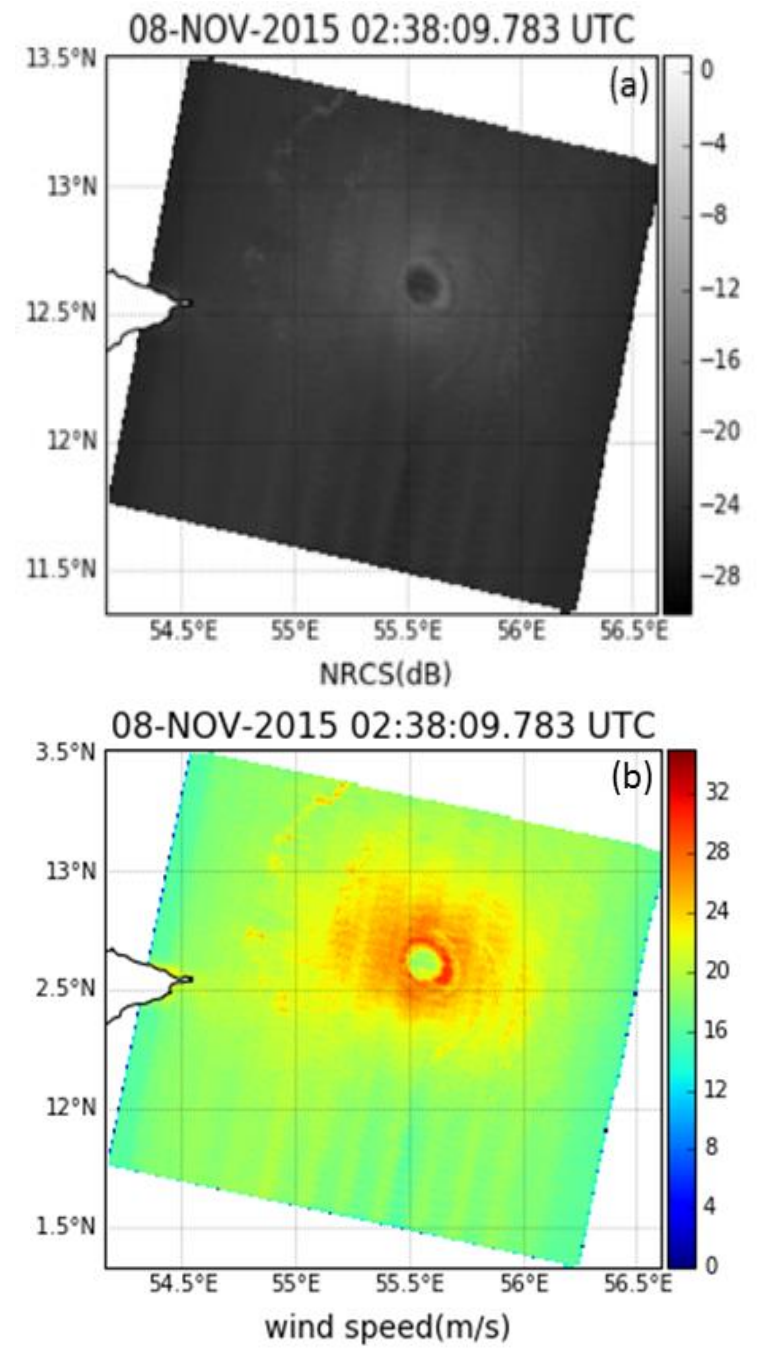

Figure 1. RISAT-1 retrieved NRCS (a) and wind speed (b).

Fig 3(a-b) displays the CER and COT derived from INSAT$3 \mathrm{D}$. It is observed that the microphysical variability is significant along the different regions of TC. COT in the eye is low as compared to its surrounding area i.e. the eyewall, which indicates the presence of relatively optically thin clouds. The eye is not devoid of any clouds which are further confirmed by noticing the existence of hydrometeors of appreciable size within it. The droplet sizes lie around the range of 30 microns (Fig. 3a) and COT lie around 40 (Fig. 3b). 

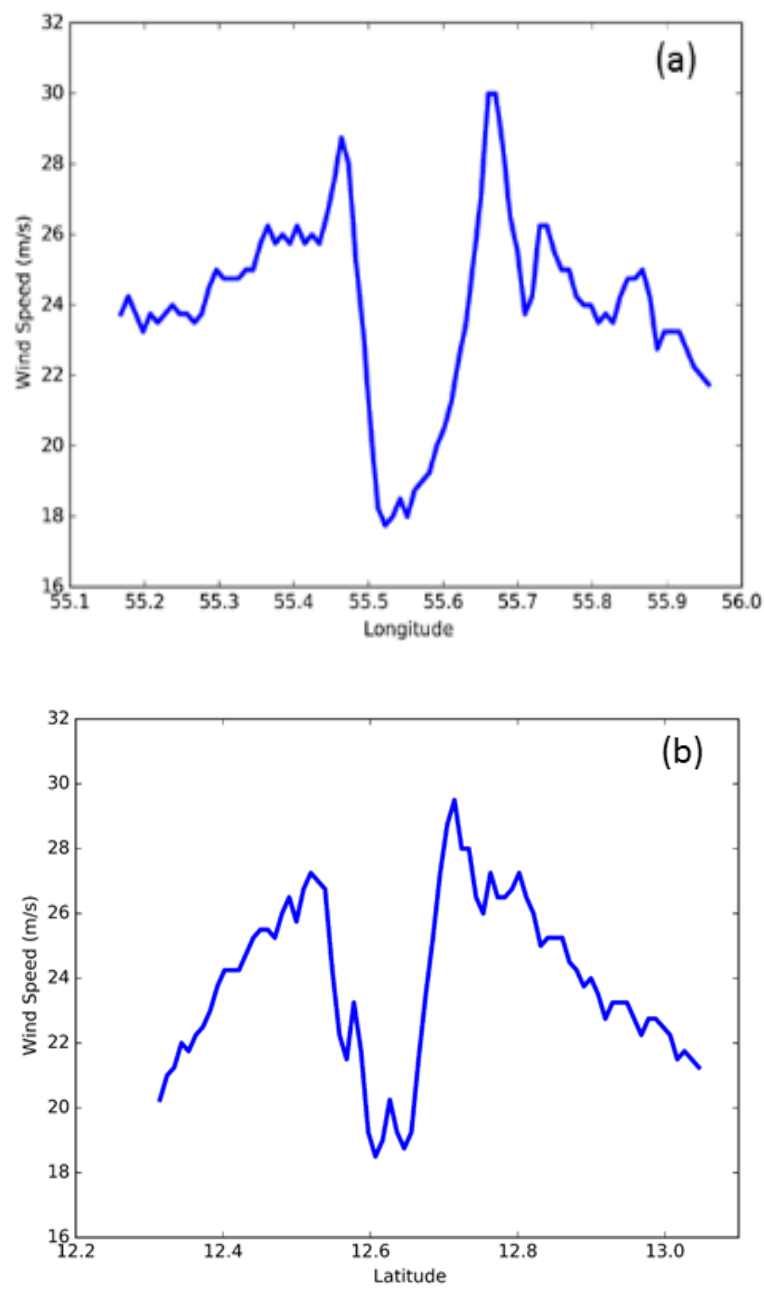

Figure 2. Variation of wind speed along a transect passing through the centre of the cyclone eye. (a) Along longitude and (b) Along latitude.

It is further noticed that larger hydrometeors as well as optically thick clouds are present in the region surrounding the eye. This indicates the area of deep convection where continuous and strong updrafts dominate resulting in bigger and heavier cloud droplets. Fig. 4 shows the CER distribution along the transect passing through the centre of the cyclone for 08 November, 20150735 UTC. It is observed that CER in the centre especially near the eye is in the range of 25-30 microns indicating the presence of low level stratocumulus clouds in the eye. The uniqueness of this study is observation of similar variation of cloud effective radius and wind speed in the cyclone transect.

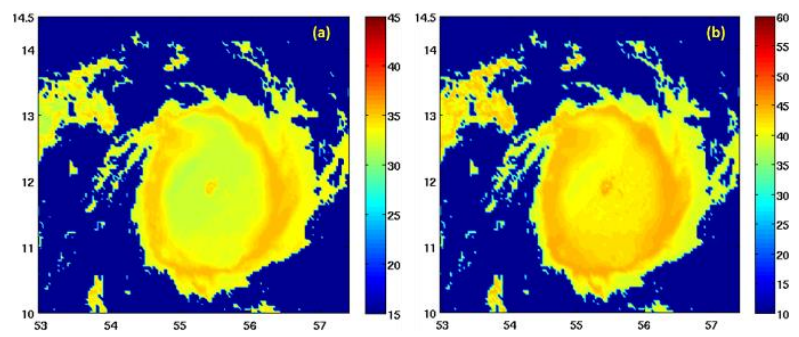

Figure 3. Spatial distribution of CMPs within the TC for 08 November 20150600 UTC derived from INSAT-3D. (a) CER and (b) COT.

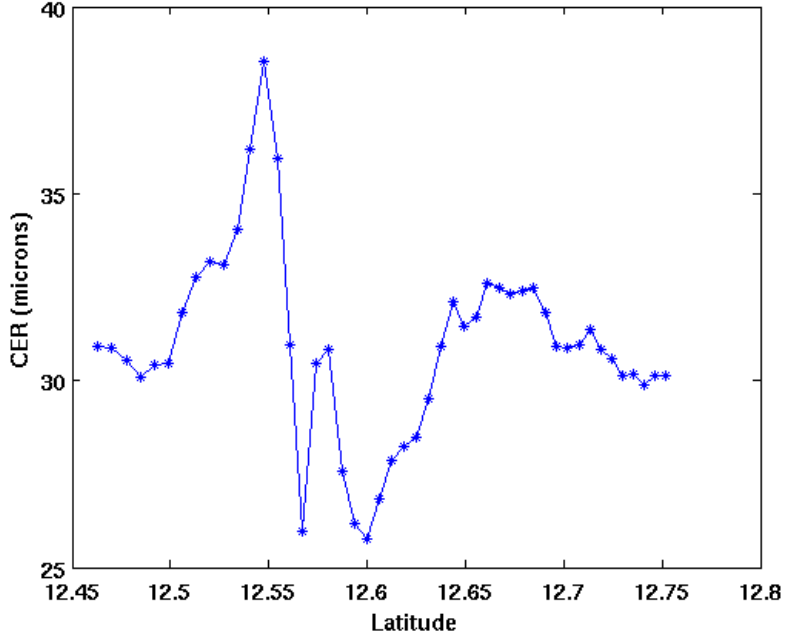

Figure 4. Distribution of MODIS derived CER along transect through the centre of the cyclone for 08 November 2015, 0735 UTC.

\section{CONCLUSIONS}

Multi-satellite optical and microwave observations of cyclone help us in understanding the complex processes taking place inside a cyclone.In this manuscript, Cyclone Megh has been analysed using synergistic observations from RISAT-1 SAR, MODIS and INSAT-3D data. The intensity of cyclone is 30 $\mathrm{m} / \mathrm{s}$ with the $16.65 \mathrm{~km}$ radius of maximum wind speed from the centre of the cyclone. It is observed that CER in the centre especially near the eye is in the range of 25-30 microns indicating the presence of low level stratocumulus clouds in the eye region. The spatial examination also brings out the existence of low-level clouds surrounding the eye. This confirms the observations made by SAR focusing the possible presence of eyewall mesovortex in case of Megh. This kind of study will be very helpful in order to understand the microphysical processes within a TC as well as serve as inputs in numerical models for cloud radiative parameterization.

\section{ACKNOWLEDGEMENT}

The authors would like to thanks Director, Space Applications Centre. The authors are thankful to Dr. Abhisek Chakraborty for their technical support. Thanks are also extended to LAADS DAAC for the MODIS data, RISAT-1 and INSAT$3 \mathrm{D}$ data teams for providing the datasets.

\section{REFERENCES}

Black, R. A., Hallett, J., 1986. Observations of the distribution of ice in hurricanes. Journal of the atmospheric sciences, 43(8), 802-822.

Cecil, D. J., Zipser, E. J., \& Nesbitt, S. W., 2002. Reflectivity, ice scattering, and lightning characteristics of hurricane eyewalls and rainbands. Part I: Quantitative description. Mon. Weather Rev., 130(4), 769-784. 
Farquhar, Mc, G. M., Black, R. A., 2004. Observations of particle size and phase in tropical cyclones: Implications for mesoscale modeling of microphysical processes. Journal of the atmospheric sciences, 61(4), 422-439.

Franklin, J. L., Lord, S. J., Marks Jr, F. D., 1988. Dropwindsonde and radar observations of the eye of Hurricane Gloria (1985). Mon. Weather Rev., 116(5), 1237-1244.

Houze Jr, R. A., 2014. Cloud dynamics. In Academic press, 104.

Jagdish, B. P. Shukla, A. Chakraborty, R. Kumar 2018b. Development of a C-band cross-polarized wind speed retrieval model from RISAT-1 synthetic aperture radar. Paper presented at National Conference on Applied Mathematical Sciences, Gujarat University, Ahmedabad, India.

Jagdish, Surisetty, A. K. V. V., Chakraborty, A, Kumar, R. 2018a. Validation of wind speed retrieval from RISAT-1 SAR images of the North Indian Ocean. Remote Sens. Lett, 5(9), 421-428.

John, J., Shukla, B. P., 2016. May. Retrieval of cloud microphysical parameters from INSAT-3D: a feasibility study using radiative transfer simulations. In Remote Sensing of the Atmosphere, Clouds, and Precipitation VI (9876, p. 98760E). International Society for Optics and Photonics.

Lander, M. A., 1999. A tropical cyclone with a very large eye. Mon. Weather rev., 127(1), 137-142.

Schenkman, A. D., Xue, M., 2016. Bow - echo mesovortices: A review. Atmospheric Research, 170, 1-13.

Wakimoto, R. M., Murphey, H. V., Davis, C. A., Atkins, N. T., 2006. High winds generated by bow echoes. Part II: the relationship between the mesovortices and damaging straightline winds. Mon. Weather Rev., 134, 2813-2829.

Wingo S. M., Knupp, K. R., 2016. Kinematic structure of mesovortices in the eyewall of hurricane Ike (2008) derived from ground-based dual-dopler analysis. American Meteorologial Society, 144, 4245-4263.

Zhang, B., Perrie W., He, Y., 2011. Wind speed retrieval from RADARSAT-2 quad-polarization images using a new polarization ratio model. J. Geophy. Res, 116, C08008, 2011.doi:10.1029/2010JC006522. 